\title{
AKREDITASI DAN PELUANG PENGUATAN KELEMBAGAAN PROGRAM STUDI PENDIDIKAN DASAR PADA PERGURUAN TINGGI
}

\author{
Udik Budi Wibowo \\ Universitas Negeri Yogyakarta \\ Email: udik_bw@uny.ac.id
}

Naskah diterima : 19 Agustus 2019, direvisi : 5 September 2019, disetujui : 25 September 2019

\begin{abstract}
Accreditation is an obligation that must be fulfilled in the implementation of study programs in tertiary institutions as stipulated in the legislation, with consequences especially on the acceptance of graduates in the world of work. The accreditation process is often seen as a tedious administrative work because it is related to the portfolio, gathering evidence of tri dharma activities and managing the institution. But, from the accreditation process, problems and shortcomings can be identified as well as opportunities for improvement. Thus the accreditation process is not just an effort to guarantee the fulfillment and/or enforcement of standards, but also is a means of continuous quality improvement. The accreditation process can encourage study program administrators and/or managers to work in synergy with internal and external stakeholders so that in the end the institutional strengthening of the study program will occur.
\end{abstract}

Keywords: accreditation, study programs, tri dharma quality, institutional strengthening.

Pengutipan: . Udik Budi Wibowo. (2019). Akreditasi dan Peluang Penguatan Kelembagaan Program Studi Pendidikan Dasar pada Perguruan Tinggi. JMIE: Journal of Madrasah Ibtidaiyah Education,3(2), 2019, 130-141. jmie.v3i2.128.

Permalink/DOI: http://dx.doi.org/10.32934/jmie.v3i2.128 


\section{PENDAHULUAN}

Akreditasi menjadi agenda penting dalam penyelenggaraan suatu program studi (prodi), karena akreditasi merupakan syarat wajib bagi keberlangsungan operasional prodi, sebagaimana diatur dalam Undang-Undang Nomor: 20 Tahun 2003 tentang Sistem Pendidikan Nasional, Undang-Undang Nomor: 12 Tahun 2012 tentang Pendidikan Tinggi, dan Permenristekdikti Nomor 32 Tahun 2016 tentang Akreditasi Program Studi dan Perguruan Tinggi. Dalam peraturan perundang-undangan tersebut dinyatakan bahwa tujuan akreditasi diantaranya adalah untuk menjamin mutu Program Studi dan Perguruan Tinggi secara eksternal baik dalam bidang akademik maupun non-akademik untuk melindungi kepentingan mahasiswa dan masyarakat. Dengan kata lain, akreditasi dimaksudkan untuk menjamin bahwa prodi berupaya menyelenggarakan tugas dan fungsi tri dharma perguruan tinggi secara berkualitas untuk memenuhi dan melayani kebutuhan mahasiswa dan masyarakat luas.

Namun demikian, proses akreditasi bagi para pengurus/pengelola prodi tidaklah mudah. Dengan latar belakang sebagai akademisi, yang dalam keseharian bertugas mengajar, meneliti dan melakukan kegiatan pengabdian masyarakat; para pengurus atau pengelola prodi yang belum berpengalaman seringkali memandang pengisian instrumen akreditasi dan pengumpulan bukti-bukti berupa portofolio kegiatan tri dharma perguruan tinggi dimaknai sebagai sekedar clerical administrative works, atau sebagai beban pekerjaan tambahan yang membosankan; sehingga muncul plesetan "membuat borang" sama dengan "membuat boring".

Selain itu tata kearsipan kegiatan civitas akademika, tenaga kependidikan dan tenaga administrasi, sebagai bahan utama pengisian borang, juga seringkali kurang mendukung. Data/informasi dan bukti-bukti kegiatan tidak ada, atau tidak dapat diakses, atau sulit ditemukan. Belum lagi, ada dosen dan tenaga kependidikan dan tenaga pendukung lain yang tidak selalu hirau akan perkembangan pengelolaan atau penyelenggaraan prodi, yang berperilaku sebagai "penumpang gratis", yang memanfaatkan prodi sebagai "sumber nafkah" namun tidak mau berkontribusi pada kemajuan dan perkembangan prodi. Lengkap sudah kesulitan pengurus prodi di dalam mengupayakan proses akreditasi yang baik. Dalam ungkapan Gaston (2018), proses akreditasi menyita banyak waktu, perhatian, dan biaya; sementara itu pada sisi lain masih perlu dipertanyakan kebermanfaatnya.

Bagaimanapun proses akreditasi merupakan kewajiban sebagaimana diatur dalam peraturan perundang-undangan di atas. Imbas dari ketentuan tersebut, akreditasi juga menjadi tuntutan kebutuhan mahasiswa dan masyarakat pengguna lulusan prodi. Berbagai kasus kegagalan lulusan perguruan tinggi dalam mengikuti seleksi dan rekrutmen pegawai dikarenakan prodi belum terakreditasi dan/atau status akreditasi prodi telah kadaluwarsa, menjadi salah satu alasan penting dari proses akreditasi prodi. Oleh karena itu, para pengurus dan/atau pengelola prodi harus membiasakan diri untuk melakukan proses akreditasi guna 
menjamin kualitas layanan pendidikan; dan bahwa penyelenggaraan program studi yang menjadi tanggungjawabnya dapat memenuhi akuntabilitas eksternal.

Proses akreditasi berlangsung secara rutin, sesuai masa berlaku status akreditasi prodi yang bersangkutan. Menurut Buku Data Statistik Pendidikan Tinggi (Pusdatin Iptekdikti Kemenristendikti, 2018) terdapat 27.779 program studi (prodi) di seluruh perguruan tinggi negeri dan swasta di seluruh Indonesia. Dari jumlah tersebut terdapat 20.899 prodi yang terakreditasi, dengan rincian 3.456 prodi terakreditasi A, 11.424 prodi terakreditasi B, dan 6.019 prodi terakreditasi C (Kemristekdikti, 2018). Masa berlaku akreditasi adalah 5 (lima) tahun, dan untuk status akreditasi minimum bagi program studi baru berlaku selama 2 tahun. Dengan demikian proses akreditasi akan terus berulang, lantas apa yang dapat dipetik dari siklus rutin akreditasi tersebut?

\section{PEMBAHASAN}

\section{Akreditasi dan kualitas pendidikan}

Perhatian terhadap akreditasi dan kualitas perguruan tinggi cenderung terus meningkat secara global, dikarenakan antara lain: internasionalisasi perguruan tinggi, tuntutan akuntabilitas dari para pemangku kepentingan, pemeringkatan (ranking) perguruan tinggi nasional maupun internasional, dan tuntutan mahasiswa dan orang tua, serta pengguna lulusan (Staub, 2019). Akreditasi dan kualitas menjadi aspek yang tak terpisahkan dalam penyelenggaraan pendidikan tinggi, sebagaimana ditegaskan oleh Eaton (Phillips \& Kinser, 2018) bahwa: " ..., quality improvement has always been the heart and soul of acrreditation, the most powerful commitment that has driven much of this enterprise for a century". Dalam tulisan lain, Eaton (2018: 130) menyatakan bahwa "Quality assurance and accreditation are about establishing, maintaining and enhancing the quality of the academic work of higher education institutions". Jadi "peningkatan kualitas" merupakan jantung dan jiwa dari akreditasi, yang menjadi komitmen paling kuat, yang mendorong banyak organisasi untuk memenuhinya, termasuk perguruan tinggi pada abad sekarang ini. Dengan akreditasi maka terjadi proses penetapan, pemeliharaan, dan peningkatan kualitas kegiatan akademik pada lembaga pendidikan tinggi.

Martin (Hernes \& Martin, 2008: 40) menyatakan bahwa "By definition, accreditation systems imply decisions on what does and does not constitute desirable quality". Lebih lanjut dikemukakan oleh kedua penulis tersebut bahwa akreditasi merujuk kepada proses pengendalian dan penjaminan kualitas, baik sebagai hasil pemeriksaan atau penilaian terhadap institusi perguruan tinggi maupun program studi di dalamnya telah terbukti memenuhi standar minimal yang ditetapkan. Dengan pengakuan kualitas dari proses akreditasi ini, maka institusi maupun prodi, dapat memetik berbagai manfaat, tidak hanya bagi lembaga sendiri, tetapi juga bagi masyakarakat dan kepentingan umum, sebagaimana dikemukakan oleh Council for Higher 
Education Accreditation (Gaston, 2016) bahwa akreditasi dapat memberikan manfaat bagi mahasiswa, masyarakat dan kepentingan umum, dalam hal seperti:

1) simbol utama dari legitimasi pendidikan tinggi,

2) pintu gerbang yang dipercaya untuk mendapatkan bantuan pendanaan dari pemerintah,

3) "otoritas yang dapat diandalkan" untuk memberikan sumbangan pribadi dalam dunia pendidikan tinggi,

4) stimulan untuk inovasi, dan kekuatan daya untuk mencapai kualitas.

5) sumber perlindungan terhadap penipuan dan penyalahgunaan,

6) sangat ekonomis dan efisien,

7) penting untuk mendapatkan lisensi dari pemerintah,

8) sangat mendukung untuk kepentingan mobilitas internasional,

9) sumber peningkatan tekanan terhadap akuntabilitas institusi dan program studi, dan

10) untuk mempertahankan fitur-fitur utama pendidikan tinggi yang telah berkontribusi pada perusahaan sebagai salah satu yang terbaik di dunia.

Berdasarkan paparan berbagai pendapat di atas dapat dinyatakan bahwa akreditasi tidak hanya sekedar pemenuhan standar yang telah ditetapkan, tetapi juga yang lebih penting lagi adalah sebagai sarana peningkatan kualitas secara berkelanjutan. Hal ini berarti proses akreditasi tidak berhenti hanya pada hasil atau status pemeringkatan akreditasi; tetapi justru yang lebih penting lagi adalah dari hasil akreditasi tersebut dapat dicermati kekurangan dan kelemahan prodi maupun institusi, dan selanjutnya dapat dikembangkan berbagai strategi dan sasaran pengembangan yang tepat dan realistik, sesuai dengan sumber daya yang dimiliki. Dengan demikian tujuan akreditasi tidak semata-mata untuk memenuhi dan melampaui standar yang telah ditetapkan; akan tetapi yang lebih penting adalah kebermanfaatannya bagi mahasiswa setelah lulus, dan bagi pengembangan masyarakat pada umumnya.

\section{Dari penjaminan kualitas menuju akuntabilitas}

Sistem akreditasi perguruan tinggi telah mengalami perkembangan sejalan dengan pemaknaan mutu dan proses penjaminan mutu organisasi. Martin (Hernes \& Martin, 2008) memaparkan bahwa pada awalnya sistem akreditasi berjalan berdasarkan pada asumsi bahwa mutu dipersamakan dengan pencapaian tujuan dan sasaran yang ditetapkan oleh institusi; artinya perguruan tinggi yang bermutu adalah perguruan tinggi yang berhasil mencapai tujuan dan sasaran yang telah ditetapkan. Pada perkembangan berikutnya, akreditasi bersandar pada asumsi bahwa kualitas sama dengan pemenuhan berbagai standar (minimal) yang telah ditetapkan sebelumnya. Dan pada akhirnya timbul pertanyaan apakah akreditasi sekedar berfokus pada penjaminan berbagai standar kualitas yang bersifat minimal tersebut, atau mengarah kepada akuntabilitas dan peningkatan kualitas. Jadi pada akhirnya, akreditasi lebih 
dari sekedar pemenuhan kualitas atau standar minimal (Marope, Wells, \& Hazelkorn, 2013); akreditasi sekarang ini menjadi proses yang mengarah kepada akuntabilitas publik kelembagaan, dengan menjalankan peningkatan kualitas secara berkelanjutan.

Perkembangan pemaknaan kualitas dan penjaminan kualitas itu sendiri sebenarnya jauh sebelumnya sudah dikemukakan oleh Sallis (1993) yang menggambarkan perkembangan sistem penjaminan mutu, yakni dari inspeksi (fokus mencari-cari atau menemukan kesalahan); lantas berlanjut menjadi kendali mutu atau quality control (penekanan pada deteksi dengan mengawal proses); berikutnya menjadi penjaminan mutu atau quality assurance (pencegahan dan komitmen pada standar yang telah ditetapkan); dan sekarang ini menjadi manajemen mutu terpadu atau total quality management (penekanan pada peningkatan mutu berkelanjutan). Dalam konteks akreditasi, Ransom, Knepler, \& Zapata-Gietl (2018) menyatakan bahwa sistem akreditasi sekarang telah bergeser dari fokus pada peningkatan kualitas menjadi akuntabilitas publik. Hal ini sejalan dengan pendapat Eaton (2016) yang menyatakan bahwa pada saat ini telah menjadi kesepakatan umum bahwa:

... the primary task of accreditation is public accountability. That means accredited status is supposed to be about protecting students -- to serve as a signal that what an institution or program says about itself is reliable, that there are reasonable chances of student success and that students will benefit economically in some way from the educational experience.

Pendapat tersebut menunjukkan bahwa akuntabilitas publik menjadi tugas utama dari akreditasi, sehingga status akreditasi harus dimaknai sebagai upaya perlindungan mahasiswa, untuk melayani sebagai pertanda bahwa apa yang dikatakan institusi dan program studi dapat dipercaya, bahwa ada kemungkinan yang rasional bagi mahasiswa untuk berhasil setelah lulus, dan bahwa mahasiswa dengan pengalaman pembelajaran di perguruan tinggi akan mendapatkan keuntungan ekonomis dalam berbagai cara atau jalan. Dengan demikian akuntabilias kelembagaan tidak semata-mata bersifat internal (inward), tetapi juga bersifat eksternal (outward). Dalam hal ini ada baiknya jika dicermati pendapat Leveille (2006) yang terkait dengan model akuntabilitas yang menekankan aktivitas sebagai berikut:

(1) permintaan pertanggungjawaban oleh pemangku kepentingan atau yang mewakili (atas nama), dengan dibarengi sanksi atau metode ganti rugi lainnya, yang menegakkan hak untuk "memaksa" perubahan/perbaikan pada lembaga pendidikan.

(2) memberikan penjelasan atau informasi kepada para pemangku kepentingan untuk melaporkan seluruh kegiatan dan hasil dari kegiatan itu.

(3) mempertanggungjawabkan kebutuhan dan pandangan pemangku kepentingan dan meresponsnya dengan memeriksa dan, (jika perlu) merevisi praktik atau meningkatkan kinerja. 
Dari paparan Levile tersebut semakin jelas bahwa dalam rangka memenuhi akuntabilitas publik, perguruan tinggi dituntut untuk mempertanggungjawabkan kepada para pemangku kepentingan, dengan memberikan informasi dan laporan seluruh kegiatan dan kinerjanya, dan selalu memperbaiki praktek/kinerjanya untuk memenuhi kebutuhan para pemangku kepentingan tersebut. Dengan demikian sistem akreditasi dapat mendorong program studi dan perguruan tinggi untuk memenuhi kebutuhan para pemangku kepentingan internal dan eksternal, dengan memperbaiki/meningkatkan kinerjanya. Selanjutnya upaya pemenuhan akuntabilitas tersebut dapat berimbas pada peningkatan kapasitas kelembagaan, baik pada tingkat program studi maupun institusi.

\section{Akreditasi, akuntabilitas dan peluang penguatan kelembagaan}

The U.S. Department of Education (Hegji, 2017) mengemukakan tujuan akreditasi antara lain:

a. Menilai kualitas program akademik pada institusi pendidikan tinggi.

b. Menciptakan budaya peningkatan mutu akademik secara berkelanjutan pada perguruan tinggi, dan merangsang peningkatan berbagai standar di lingkungan perguruan tinggi.

c. Melibatkan para dosen dan tenaga kependidikan secara menyeluruh di dalam perencanaan dan evaluasi perguruan tinggi; dan

d. Menetapkan kriteria untuk sertifikasi dan lisensi profesi, serta penawaran kursus peningkatan, sama seperti proses penyiapan/pendidikan profesi yang bersangkutan.

Tujuan akreditasi di atas, apabila dicermati tampak bahwa penilaian kualitas program akademik hanya merupakan salah satu dari empat tujuan akreditasi. Tujuan dari akreditasi yang lain adalah menciptakan budaya peningkatan mutu berkelanjutan. Tagihan akreditasi pada dasarnya adalah kualitas proses dan hasil penyelenggaraan pendidikan pada prodi dan/atau institusi. Tuntutan masyarakat (publik) terhadap kualitas ini selalu berkembang dari waktu ke waktu sesuai dengan perkembangan zaman. Oleh karena itu seluruh komponen prodi dan institusi perlu kesadaran dan budaya mutu untuk selalu meningkatkan kualitas secara berkelanjutan terhadap penyelenggaraan pendidikan yang menjadi tanggungjawabnya.

Akreditasi juga menuntut keterlibatan dosen dan tenaga kependidikan (termasuk tenaga pendukung/administrasi) secara penuh karena mereka merupakan subyek utama yang bertugas dan bertanggungjawab dalam memberikan layanan pembelajaran dan administratif. Layanan pembelajaran (akademik) tidak dapat berjalan secara optimal apabila tidak didukung dengan layanan non-akademik, termasuk layanan administratif. Oleh karena itu akreditasi dapat berhasil apabila dosen dan tenaga kependidikan dilibatkan dalam perencanaan dan evaluasi, tidak sekedar pada saat implementasi kegiatan saja. Dengan pelibatan dalam perencanaan maka para dosen dan tenaga kependidikan dapat mengetahui arah kegiatan 
semenjak awal, dan selanjutnya tumbuh rasa ikut memiliki (sense of belonging) dan rasa tanggung jawab (sense of responsibility) yang dapat memperkuat komitmen untuk memberikan layanan akademik dan non-akademik yang berkualitas berkelanjutan.

Akreditasi juga terkait dengan sertifikasi dan lisensi. Sertifikasi merupakan pengakuan resmi terhadap kemampuan seseorang untuk melakukan tugas sesuai bidang keahliannya, yang diperoleh melalui pendidikan dan/atau pelatihan oleh lembaga yang sudah terakreditasi. Oleh karena itu sertifikasi keahlian akan diakui apabila dikeluarkan atau diterbitkan oleh lembaga/institusi yang sudah terakreditasi, seperti sertifikasi pendidik profesional yang diakui oleh masyarakat adalah sertifikat pendidik yang dikeluarkan oleh program studi kependidikan yang memiliki status akreditasi diutamakan peringkat Unggul (A), atau minimal Baik Sekali (B). Implikasi dari sertifikasi dan akreditasi ini, adalah sudah seharusnya lisensi (ijin berpraktek) diberikan hanya kepada seseorang yang memiliki sertifikat dari lembaga pendidikan yang memenuhi syarat akreditasi tersebut.

Dengan keterkaitan antara akreditasi, sertifikasi, dan lisensi tersebut maka suatu program studi perlu berupaya memperkuat berbagai komponen kelembagaannya agar dapat memenuhi persyaratan dan peringkat akreditasi yang diharapkan, tetapi juga dapat mengembangkan dan meningkatkan kinerjanya secara berkelanjutan. Dalam konteks ini, Mati (2018) menemukan berbagai perguruan tinggi telah mengembangkan indikator kinerja utama berdasarkan standar akreditasi, sehingga mudah diukur kemajuan dan ketercapainnya. Berdasarkan indikator tersebut maka dapat mengarahkan dan mengoptimalkan pengelolaan sumber daya yang dimiliki untuk meningkatkan kinerja institusi, dan sekaligus untuk memenuhi persyaratan akreditasi. Dengan kata lain, akreditasi pada dasarnya dapat menjadi pemicu dan pemacu penguatan kelembagaan program studi.

Penguatan kelembagaan dapat dipersamakan dengan pengembangan kemampuan atau pembangunan kapasitas, atau dalam istilah bahasa Inggris sebagai capacity building atau capacity development. Kapasitas merupakan kemampuan seseorang, organisasi, dan masyarakat secara keseluruhan dalam mengelola berbagai urusan (tugas dan fungsinya) sehingga berhasil dengan baik. Adapun pengembangan kapasitas adalah proses dimana individu, organisasi, dan masyarakat secara keseluruhan dalam memperlancar, memperkuat, menciptakan, menyesuaikan, dan mempertahankan kemampuannya sepanjang waktu (OECD, 2006; UNDP, 2009; Bester, 2015). Sejalan dengan pemikiran tersebut maka penguatan kelembagaan dapat berlangsung pada tataran pengurus/pengelola prodi, level program studi, dan level perguruan tinggi; bahkan pada tingkat lingkungan kebijakan yang menaungi perguruan tinggi.

Berdasarkan paparan di atas, maka dapat dikemukakan bahwa akreditasi sebagai upaya penjaminan mutu eksternal, dapat menjadi pemicu dan pemacu prodi dan institusi untuk memenuhi dan melampaui standar yang telah ditetapkan, dan selanjutnya dapat membawa imbas pada penguatan kelembagaan melalui berbagai cara, sebagai berikut: 
a. Pembiasaan pengambilan keputusan, perencanaan, dan bertindak berbasis data.

Akreditasi pada dasarnya berbasis kesejawatan dan bersandar pada evaluasi diri, serta berbasis bukti (Marope, Wells, \& Hazelkorn, 2013: 130). Dengan evaluasi berbasis data dan bukti, maka akar permasalahan dapat ditemukenali (diidentifikasi) secara tepat, dan selanjutnya dapat dikembangkan strategi penyelesaiaannya beserta sasaran yang realistik. Dengan demikian dalam proses akreditasi ini terjadi proses penguatan kelembagaan dalam hal peningkatan kapasitas dan kualitas pengambilan keputusan dan perencanaan sehingga menghasilkan keputusan-keputusan yang semakin berkualitas dan rencana yang realistik.

b. Peningkatan tertib administrasi kearsipan dalam penyelenggaraan institusi.

Akreditasi merupakan pembuktian tingkat kualitas dari penyelenggaraan program studi. Leveille (2006) menyatakan bahwa yang diperlukan dalam sistem akreditasi dan akuntabilitas adalah budaya bukti, data/informasi yang dibutuhkan tersedia dan konsisten pada tingkat prodi, institusi, atau level sistem. Ketersediaan dan konsistensi bukti-bukti tersebut perlu dikelola dengan efektif dan efisien agar mudah diakses dan cepat ditemukan apabila diperlukan. Oleh karena itu hasil akreditasi yang baik memerlukan tata kelola kearsipan yang tertib dan pengembangan sistem dan mekanisme penggunaan yang mudah dan cepat, dengan didukung budaya sadar mutu seluruh civitas akademika dan tenaga kependidikan dengan selalu mengarsipkan semua bukti-bukti kegiatan tri dharma dan pendukungnya.

c. Perubahan dan pembaharuan (inovasi) akademik dan non-akademik.

Untuk memperoleh hasil akreditasi yang unggul, program studi atau perguruan tinggi tidak bisa hanya sekedar memenuhi standar minimal, tetapi diperlukan kinerja yang dapat melampaui standar minimal tersebut. Sehubungan dengan itu, agar dapat melampaui standar minimal diperlukan berbagai strategi perubahan, pembaharuan atau inovasi pada aspek penyelenggaraan akademik dan non-akademik maupun layanan administrasi. Inovasi, perubahan dan pembaharuan ke arah yang lebih berkualitas sudah selayaknya menjadi budaya kerja di lingkungan perguruan tinggi, karena seperti dikatakan Salvioni, Franzoni, \& Cassano (2017) bahwa universitas merupakan wahana utama untuk mengeksplorasi, menguji, mengembangkan, dan mengomunikasikan perubahan/pembaharuan yang efektif dan berkelanjutan. Dengan inovasi-inovasi tersebut maka dapat terbentuk mekanisme penguatan kelembagaan perguruan tinggi, karena inovasi tidak akan berjalan dengan baik apabila tidak didukung dengan kapasitas kelembagaan yang memadai.

d. Pembentukan dan pengembangan budaya mutu berkelanjutan.

Penjaminan mutu dapat diekspresikan dalam kredo "... getting things right first time, every time" (Sallis, 1993, 1996, 2002), yakni sebagai upaya mendapatkan hasil yang berkualitas dari 
pertama kali sampai untuk selamanya. Untuk itu dalam lingkungan prodi perlu dikembangkan budaya mutu (Sattler \& Sonntag, 2018) yakni suatu budaya organisasi yang mengarah pada peningkatkan kualitas secara permanen, yang mencakup elemen budaya/psikologis berupa nilai-nilai bersama, kepercayaan, harapan dan komitmen terhadap kualitas; dan elemen struktural/ manajerial yang menetapkan proses untuk meningkatkan kualitas, dan menjalin koordinasi berbagai upaya individu. Proses akreditasi merupakan upaya penjaminan kualitas kinerja prodi, untuk itu elemen individu dan struktural harus memiliki kesadaran dan budaya mutu untuk bersama-sama mewujudkan penyelenggaraan pendidikan yang berkualitas sehingga menghasilkan peringkat akreditasi yang unggul.

e. Pembangunan soliditas dan sinergitas antar pemangku kepentingan.

Hernes \& Martin (2008) mengemukakan bahwa akreditasi sebagai fungsi akuntabilitas publik memerlukan peran penting dari sejawat untuk berbagi pengetahuan, keterampilan atau keahlian, dan pengalaman, termasuk untuk pembandingan (benchmarking). Sementara itu dalam sistem akreditasi, khususnya APS4.0 cakupan instrumen akreditasi tidak hanya mengukur input dan proses, tetapi juga mengukur outputs dan outcomes yang berada pada lingkungan eksternal. Oleh karena itu dalam proses akreditasi diperlukan kerjasama yang solid dan sinergis antar seluruh pemangku kepentingan program studi atau institusi, baik internal maupun eksternal. Dengan kata lain dalam proses akreditasi tersebut diperlukan soliditas dan sinergitas antar seluruh pemangku kepentingan. Fullan (2010) menyatakan bahwa seluruh komponen sistem harus berjuang bersama-sama apabila organisasi ingin berhasil menuju perubahan dan pembaharuan. Demikian pula dalam proses akreditasi, seluruh pemangku kepentingan prodi/institusi harus saling bekerjasama, berkoordinasi, dan bersinergi untuk memenuhi dan melampui standar kualitas yang ditetapkan agar dapat diperoleh peringkat akreditasi yang unggul; dan pada akhirnya terjadi penguatan kapasitas kelembagaan prodi dan institusi.

\section{KESIMPULAN}

Proses akreditasi merupakan penjaminan mutu eksternal yang dapat menjadi pemicu dan pemacu penguatan kelembagaan program studi dan institusi perguruan tinggi, antara lain melalui (a) Pembiasaan pengambilan keputusan, perencanaan, dan bertindak berbasis data; (b) Peningkatan tertib administrasi kearsipan dalam penyelenggaraan institusi; (c) Perubahan dan pembaharuan (inovasi) akademik dan non-akademik; (d) Pembentukan dan pengembangan budaya mutu berkelanjutan; dan (e) Pembangunan soliditas dan sinergitas antar pemangku kepentingan. Dengan demikian agar proses akreditasi dapat berhasil dengan baik, maka seluruh pemangku kepentingan internal dan eksternal dari program studi dan perguruan tinggi harus membangun mekanisme kerjasama, koordinasi, dan sinergi yang kuat (solid) dalam 
meningkatkan kualitas kinerja secara berkelanjutan. Demikian mudah-mudahan paparan ini dapat memberikan inspirasi untuk memperkuat kapasitas kelembagaan, dan selanjutnya dapat dijadikan modal untuk mendapatkan peringkat akreditasi sebagaimana diharapkan.

\section{DAFTAR PUSTAKA}

Bester, A. (2015). Capacity development: A report prepared for the United Nations Department of Economic and Social Affairs for the 2016 Quadrennial Comprehensive Policy Review. QPCR2016 - Study on Capacity Development - 28 Nov 2015 . Tersedia online pada https://www.un.org/en/ecosoc/qcpr/pdf/sgr2016deskreview-capdev.pdf. Diunduh pada 13 Agustus 2019.

Direktorat Jenderal Pembelajaran dan Kemahasiswaan. (2017). Pedoman penyelenggaraan pendidikan profesi guru. Jakarta: Kementeritan Riset, Teknologi dan Pendidikan Tinggi.

Eaton, J. S. (December 1, 2016). "Pivotal year for accreditation”. Inside Higher Ed. Tersedia online pada https://www.insidehighered.com/views/2016/12/01/growing-federalrole-accreditation-will-have-drawbacks-essay. Diunduh pada 13 Agustus 2019. . (2018). Combating academic corruption: Quality assurance and accreditation. International Higher Education, 2(93), 8-9. Tersedia online pada https://doi.org/10.6017/ihe.0.93.10426. Diunduh pada 13 Agustus 2019.

Fullan, M. (2010). All systems go: The change imperative for whole system reform. California: Corwin A SAGE Company.

Gaston, P. L. (2018). Assessment and accreditation: An imperiled symbiosis. Occasional Paper \#33. Urbana, IL: University of Illinois and Indiana University, National Institute for Learning Outcomes Assessment (NILOA). Tersedia online pada http://learningoutcomesassessment.org/occasionalpaperthirtythree.html._Diunduh pada 14 Agustus 2019.

Hegii, A. (2017). An Overview of Accreditation of Higher Education in the United States. Congressional Research Service Report. Tersedia online pada https://fas.org/sgp/crs/misc/R43826.pdf, diunduh pada 12 Agustus 2019.

Hernes, G. \& Martin, M. (2008). Accreditation and the global higher education market. Policy Forum No. 20. Paris: International Institute for Educational Planning - UNESCO. Tersedia online pada https://unesdoc.unesco.org/ark:/48223/pf0000163514?posInSet=1\&queryId=NEXPLORE-12891a59-3d94-4096-8b02-94673304c64a diunduh pada: 13 Agustus 2019. 
Kementerian Riset, Teknologi, dan Pendidikan Tinggi. (2018) Statistik pendidikan tinggi 2018. Tersedia online pd https://ristekdikti.go.id/epustaka/buku-statistik-pendidikantinggi-2018/. Diunduh pada 14 Agustus 2019

Leveille, D.E. (2006). Accountability in Higher Education: A Public Agenda for Trust and Cultural Change. Berkeley: Center for Studies in Higher Education - University of California. Tersedia online pada: https://cshe.berkeley.edu/sites/ default/files/publications/leveille accountability.20.06.pdf. Diunduh pada 17 Agustus 2019.

Marope, P.T.M., Wells, P.J. \& Hazelkorn, E. (eds) (2013). Rankings and accountability in higher education: Uses and misuses. Paris: UNESCO. Tersedia online pada https://unesdoc.unesco.org/ark:/48223/pf0000220789.

Mati, Y. (2018), "Input resources indicators in use for accreditation purpose of higher education institutions", Performance Measurement and Metrics, Vol. 19 No. 3, pp. 176-185. https://doi.org/10.1108/PMM-02-2018-0006. Diunduh pada 18 Agustus 2019.

Organization for Economic Co-operation and Development. (2006). The challenge of capacity development: Working toward good practice. Paris: OECD. Tersedia online pada http://www.fao.org/fileadmin/templates/capacitybuilding/pdf/ DAC paper final.pdf. Diunduh pada 18 Agustus 2019.

Phillips, S.D. \& Kinser, K. (eds.). (2018). Accreditation on the edge: Challenging quality assurance in higher education. Baltimore: Johns Hopkins University Press.

Quapp, U. (2018) Recent Development in Higher Education Accreditation in Germany (2018). $\quad$ https://www.sryahwapublications.com/journal-of-law-and-judicialsystem/pdf/v1-i2/2.pdf

Ransom, T., Knepler, E. \& Zapata-Gietl, C. (2018). New approaches to judging quality in higher education: Profiles of emerging methods apart from traditional accreditation. CHEA/CIQG Publication Series. Council for Higher Education Association

Sallis, E. (1993, 1996, 2002). Total Quality Management in Education. Philadelphia - London: Kogan Page Limited.

Salvioni, D.M., Franzoni, S. \& Cassano, R. (2017). Sustainability in the higher education system: An opportunity to improve quality and image. Sustainability, 2017, 9, 914. Tersedia online pada: http://www.mdpi.com/journal/sustainability. Diunduh pada 15 Agustus 2019.

Sattler, C \& Sonntag, K. (2018). Quality cultures in higher education institutionsDevelopment of the quality culture inventory. Knowledge and Space. Springer Link. 
Tersedia online pada: https://link.springer.com/chapter/10.1007/978-3-319-755939_9. Diunduh pada 15 Agustus 2019.

Staub, D. (2019) 'Another accreditation? what's the point?' effective planning and implementation for specialised accreditation, Quality in Higher Education, DOI: 10.1080/13538322.2019.1634342. Diunduh pada 18 Agustus 2019.

United Nations Development Programme. (2009). Capacity development: A UNDP primer. New York: UNDP's Capacity Development Group. Tersedia online pada https://www.undp.org/content/dam/aplaws/publication/en/publications/_capacitydevelopment/capacity-development-a-undp-primer/CDG PrimerReport final web.pdf 